\title{
Challenges and Issues of E-Learning Using Education Cloud - A Review in Context of Covid-19 Pandemic
}

\author{
Saifallah Al Kati \\ College of Computer Science and Information Science \\ Imam University \\ Riyadh, Saudi Arabia
}

\author{
Muhammad Asif Khan \\ College of Computer Science and Engineering \\ Taibah University \\ Madinah, Saudi Arabia
}

\begin{abstract}
During the recent Coronavirus (Covid-19) pandemic the traditional education system almost halted throughout the world. However, in order to continue with the education without wasting students time most of the countries transferred their teaching online. Although the online teaching is widely used but there are many challenges and security issues specially when the education is disseminated using education cloud. In this article we examine and review such challenges and security issues that may impact students and teachers in various educational institutions in Saudi Arabia. A review of hybrid cloud model is presented in order to benefit across institutions. The research also articulates different ways which can be adopted by educational institutions to provide smooth online teaching due to pandemic of covid-19. We also present some solutions that may help overcome challenges and secure a robust cloud infrastructure.
\end{abstract}

Keywords: cloud computing; e-learning; issues; challenges; online teaching; covid-19

\section{INTRODUCTION}

A respiratory disease due to Coronavirus (Covid-19) originated from bats in China in late 2019 [1]. The virus spread out throughout the world very rapidly. Businesses, industries, educational institutions and recreational activities were shut down in order to prevent pandemic from spreading at large scale. All researchers and practitioners agreed that social distancing is the only cure to protect from pandemic and this is why people were advised to maintain a distance from interacting each other. All gaits of life were affected and education is one of them where student-teacher interaction was inevitable. Therefore, educational institutions were shut down in compliance with social distancing rule. Various institution adopted e-learning strategy in order to continuously providing teaching to students. In Saudi Arabia enormous precautionary measures were taken in all areas in order to prevent from virus spread across the country. The ministry of education suspended in-person teaching activities in all public and private educational institutions and instructed to continue teaching online without delay of even one day [2].

In order to provide a seamless teaching to students online and assessing them though various assessments methods, resources should be available all the time. Since each institution is responsible to ensure resources are in place in institutional servers it becomes more complex, expensive and hectic. The best solution is to use a cloud computing where all teaching and assessment materials are available with convenience and ease.

\subsection{Cloud computing}

A cloud is a group of servers that are available on internet and provide different functionality to various clients. Servers have different types such as application server, database server, web server etc. Cloud computing refers to availability of computing and storage resources i.e. servers over internet. These resources are available to many users over internet at a time without compromising of data loss and data security. Cloud computing helps organizations to prevent infrastructure costs and still can use desired applications and manage data with minimum cost without any hassle. Servers are available in data centers, which enable users to access their data and applications without maintaining and updating them. Cloud computing is more useful for small businesses where technology infrastructure is more expensive than outsourcing the required resources.

\subsection{Cloud services}

There are different cloud computing service models that are available to users by different cloud service providers. [3] described three service models that are common in industry i.e. Infrastructure as a Service (IaaS), Platform as a Service (PaaS) and Software as a Service (SaaS).

\subsubsection{Cloud services}

A cloud service provider offers virtual data storage and servers to users who may develop their own applications using the resources available in the cloud. In this service model operating systems, data storages and various applications are maintained by cloud service providers. A business client may choose the services as per requirements and pay the prescribed charges based on the usage of the services. This model is scalable which does not require any installation on premises and reduces cost. Figure 1A shows this model. 


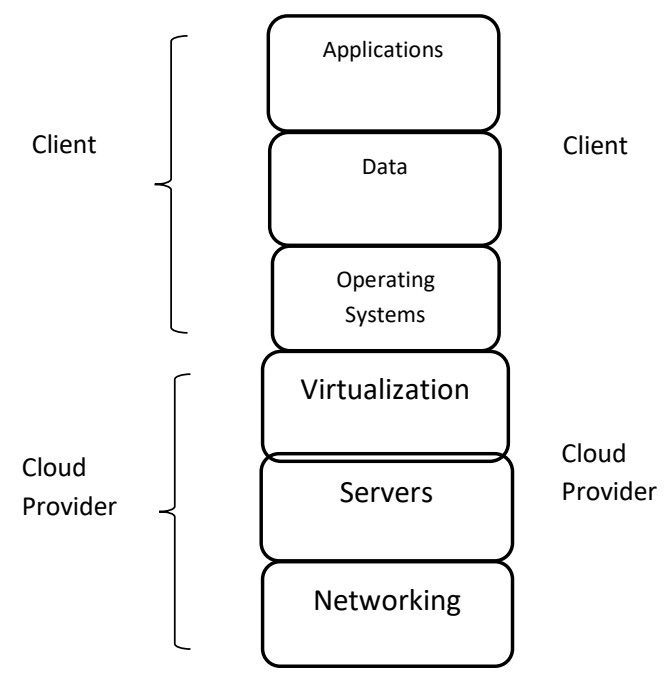

A

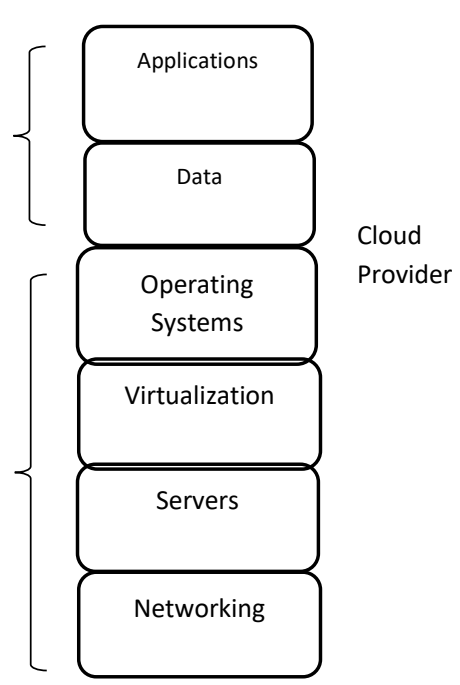

B

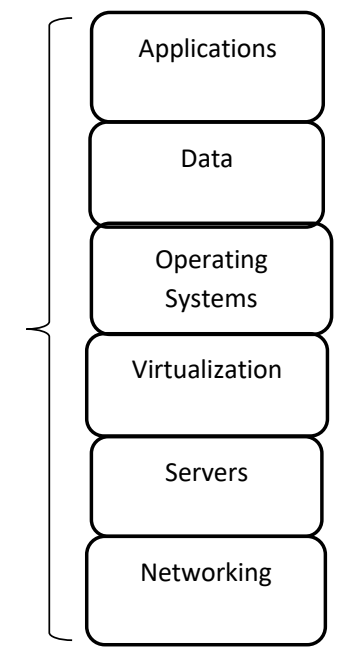

C

Figure 1. Cloud services infrastructure

\subsubsection{Platform as a Service (PaaS)}

This model provides users with a platform to develop, manage and test their applications that abridges the development process. The cloud provider provides servers, storage and network resources to users for developing applications and manage them by either users or the service provider. Figure $1 \mathrm{~B}$ depicts the PaaS model.

\subsubsection{Software as a Service (SaaS)}

In this service model, cloud service provider hosts software applications and facilitates users to access the software on demand through internet. Users may develop their own business application using the software and either save data locally or in the cloud. In this, users always find updated software and its functionalities without any hassle of availability of new version of the software. Figure $1 \mathrm{C}$ shows this model.

In order to deploy cloud services there are mainly three types of cloud i.e. public cloud, private cloud and hybrid cloud.

Public cloud allows users to use the infrastructure provided by a cloud service provider. The cloud infrastructure is established and maintained at the premises of cloud service provider and thus users do not have any control on that. Various clients share the resources which, in turn reduces cost, but the security may be compromised and vulnerability exists. In private cloud infrastructure is dedicated to one company or user without any sharing of resources. In this type of cloud security is high, but if clients requires infrastructure can be provided to the client's premises for more security and control of the resources. A hybrid cloud is composed of public and private clouds. It is usually used by those companies which give access of products to their customers and interact with them through public cloud whereas the company maintains private data in a private cloud.

\subsection{Research Question}

In this research we strive to answer the following research question:
What are security challenges and issues of cloud computing that hamper online higher education in Saudi Arabia.

\subsubsection{Research Motivation}

Cloud computing services have been adopted throughout the globe due to their usefulness and economic feasibility. In order to fulfil educational institutions education cloud has been in use by different organizations and various educational tools and services are provided by the cloud service providers. In Saudi Arabia many universities are using education cloud to provided optimum teaching and learning facilities. However, there have been several issues and challenges which universities experience around the world. Due to such issues educational institutions face difficulties to provide required level of quality education. We aspired to find challenges and issues that universities in Saudi Arabia face and need to resolve them in order to continue providing quality education online.

\section{LITERATURE REVIEW}

Cloud computing paradigm facilitates sharing of pool of resources and its scalability feature convinces businesses to adopt this paradigm at low cost. Rapid increase in adoption of latest technology has encouraged educational institutions of higher learning to use cloud computing in order to develop global interaction, communication and cooperation [4]. In the prevailing situation due to Covid-19 pandemic educational institutions are planning to transform formal education to online education or e-learning. It is imperative for educational establishments to concentrate on imparting effective education and learning instead of focussing on technology infrastructure. Cloud computing paradigm ensures that educational institutions focus on education and effective delivery of contents to students without developing and installing software and applications [5]. In order to communicate and collaborate with other educational institutions it is necessary to have a common place where organizations could share their resources such as course material, assessments, projects etc. A hybrid cloud computing model was presented by [6] for higher educational institutions in Saudi Arabia in which such sharing of resources proposed. E-learning was adopted in 
Saudi Arabia somewhat is 1990s, but a sharp rise happened due to growth in technology and internet [27]. Saudi government set up an IT plan to induct technologies at all levels especially higher education and established distance learning centers [28]. Universities in Saudi Arabia have been active in e-learning such as King Abdulaziz University, King Fahad University of Minerals and Petroleum, Taibah University, King Saud University, King Faisal University, Qassim University etc.

In view of recent Covid-19 pandemic spread, the ministry of education Saudi Arabia suspended all formal teaching in public and private institutions beginning from March 8, 2020 until further notice [7]. However, the ministry immediately launched e-learning through learning management system in order to continue studies without disruption and to save students time. The e-learning provides convenience to both students and faculty in terms of place, time and learning resources. Due to its convenience, e-learning is being adopted throughout the globe and it is replacing the traditional teaching system [8]. Faculty members can share and update the same teaching material and deliver it with confidence to their students.

However, researchers have identified some challenges in implementation of e-learning such as scalability and infrastructure that need to be updated and configured with the growth of workloads [9]. In a study conducted for Kenyan Higher Education this has been reported that in success of elearning, apart of computing technology, quality and character of an institution plays a significant role [10]. Although initially e-learning was considered as a mean of convenience, collaboration, cost effectiveness, scalability and availability, but now it is an essential continuous source of education for students in view of covid19 pandemic. In turn, cloud computing services are gaining popularity and many challenges are also increasing accordingly. In a study [11] some challenges such as data privacy and cloud infection were reported. Some other challenges like technology awareness, infrastructure, culture, instructor competency and readiness from students and faculty were discussed in developing countries [8]. The increasing growth in technology has fascinated the Generation $\mathrm{Y}$ who is e-learning prone due to its convenience and availability [12] and therefore, it seems despite of various challenges and issues e-learning will become an effective and popular mode of study among the large population of students [13]. Some challenges and security issues in cloud have been reported such as surveillance of virtual machine from a host or another virtual machine, data access by malicious program, inadequate provisions in service legal agreement (SLA) and failure in complying standards [14][15][16].

In order to meet the demands of e-learning in Saudi Arabia, the ministry education, Saudi Arabia has established a national e-learning center (NeLC) with the aim to provide quality education. The center provides licenses to the entities which provide e-learning education as per standards defined by the NeLC [17]. In a study [18] various issues and concerns were examined in adoption of cloud computing in public sector. In view of increasing demands of cloud computing services are being provided in educational institutions. In another study [19], the growing trend of e-learning in Saudi Arabia is highlighted and various factors such as support, training, incentives to faculty for e-learning growth have been mentioned. Many prominent cloud service providers such as Microsoft, Google and IBM are providing attractive programs for education such as GoogleDocs, Google Drive, Office 365 and IBM Academy [20].

\section{MATERIAL AND METHODS}

In order to determine the trend in e-learning security challenges in issues in education cloud, qualitative methodology is appropriate which provides a set of different methods for deep insight. We collected qualitative data from various articles, interview meetings and reports, in order to analyze the issues and challenges in e-learning through education cloud. Since our focus is Saudi Arabia, we collected relevant data using different methods stated above.

Qualitative methods are flexible and provide opportunity to design and improve system in view of people's experiences and perceptions. Qualitative research helps to unfold findings in natural setting without manipulating natural phenomenon [21]. The data collected by these methods is from real world and can be adapted to explore new opportunities. Case studies provide data that is generated in real time and can be verified. Case studies use face on face interviews, focus groups and survey instruments for collecting first hand data from various sources. In our study we used case studies, which use cloud technology especially education cloud for e-learning. The case studies help to determine various issues and challenges that educational institutions face during online teaching especially in Saudi Arabia. The data collected from literature provided us foundation to investigate the issues and challenges in Saudi educational institutions. In order to collect data investigated higher educational institutions that use educational cloud. We selected five major public higher educational organizations in Saudi Arabia which agreed to provide data on anonymous condition. We contacted the responsible persons of respective departments in the institutions in order to collect data on various issues and challenges. For this purpose, we held faceto-face meetings and collected first hand data. Also, we uploaded a questionnaire on a website and received 109 responses from all the five institutions, out of which 98 found to be complete and trustworthy. In order to measure reliability, the internal consistency in responses was checked and standard general test Cronbach's Alpha was conducted that resulted in 0.67 value. The Cronbach's alpha value shows the reliability of the responses we received. Table 1 shows some sample of questions that were asked in the questionnaire on Likert's scale.

Table - 1. Sample questions from questionnaire

\begin{tabular}{|l|l|}
\hline No. & \multicolumn{1}{|c|}{ Question phrase } \\
\hline 1 & $\begin{array}{l}\text { We consider our resources including teaching } \\
\text { material secure online }\end{array}$ \\
\hline 2 & $\begin{array}{l}\text { Our students did not experience difficulties due to } \\
\text { immediate shift online during Covid-19 pandemic }\end{array}$ \\
\hline 3 & $\begin{array}{l}\text { We have enough knowledge of technological } \\
\text { infrastructure to support e-learning }\end{array}$ \\
\hline 4 & $\begin{array}{l}\text { Our online system is robust and cloud services } \\
\text { never failed during teaching }\end{array}$ \\
\hline 5 & $\begin{array}{l}\text { We are satisfied with the performance of cloud } \\
\text { services and e-learning }\end{array}$ \\
\hline 6 & $\begin{array}{l}\text { Students were comfortable during online } \\
\text { assessments and no issues raised }\end{array}$ \\
\hline & \multicolumn{2}{|c}{} \\
\hline
\end{tabular}




\begin{tabular}{|l|l|}
\hline 7 & $\begin{array}{l}\text { Instructors experienced difficulties in preparing } \\
\text { online assessments }\end{array}$ \\
\hline 8 & $\begin{array}{l}\text { Cloud services provided all necessary tools required } \\
\text { for preparing online assessments }\end{array}$ \\
\hline 9 & $\begin{array}{l}\text { Our cloud service provider support has been } \\
\text { available whenever we needed }\end{array}$ \\
\hline 10 & $\begin{array}{l}\text { Our students cooperated in online learning and } \\
\text { evaluation caused by pandemic covid 19 }\end{array}$ \\
\hline
\end{tabular}

The severity or significance of security issue in organizations was determined through the data collected by interviews and questionnaire. We used Likert's scale 1-5in order to determine significance in which, 5 means very high and 1 indicates very low significance of the issue or challenge.

\section{RESULTS AND DISCUSSION}

We collected data through various literature, interviews, documents, questionnaire in order to find out the difficulties, challenges and issues in public education institutions in Saudi Arabia. The institutions used the cloud computing services and provided information about their experience.

Table 2 shows the number of respondents for the significance of the issues and challenges in the public educational organizations (mentioned as A through E for privacy) in Saudi Arabia. These issues and challenges have been extracted from the literature as well as question phrases in questionnaire that were reconfirmed by the respondents.

Table - 2. Number of respondents for significance of issue/challenge

\begin{tabular}{|c|c|c|c|c|c|c|c|c|}
\hline \multirow[b]{2}{*}{ Issue/Challenge } & \multirow{2}{*}{$\begin{array}{l}\text { Literature/ } \\
\text { Reference }\end{array}$} & \multicolumn{5}{|c|}{ Significance } & \multirow[b]{2}{*}{ Mean } & \multirow{2}{*}{$\begin{array}{l}\text { Standard } \\
\text { Deviation }\end{array}$} \\
\hline & & $\begin{array}{l}\text { Very } \\
\text { high }\end{array}$ & High & Neutral & Low & Very low & & \\
\hline Privacy & [11][18][21] & 45 & 38 & 3 & 8 & 4 & 4.1428 & 0.54300 \\
\hline Data security, risk & {$[21]$} & 36 & 39 & 2 & 13 & 8 & 3.8367 & 0.49734 \\
\hline Infrastructure & [8] & 38 & 41 & 4 & 7 & 7 & 3.9489 & 0.51536 \\
\hline Quality of education & {$[24][25]$} & 43 & 44 & 1 & 8 & 2 & 4.2040 & 0.56982 \\
\hline Culture and training & [25] & 28 & 32 & 8 & 12 & 18 & 3.4081 & 0.42443 \\
\hline Cloud control & {$[26]$} & 41 & 38 & 4 & 8 & 6 & 3.9897 & 0.51493 \\
\hline Performance & [26] & 39 & 41 & 3 & 10 & 5 & 4.0102 & 0.52334 \\
\hline
\end{tabular}

As we can see from the above figure 1 the majority of the respondents considered quality of education as most significance issue. Usually, in Saudi Arabia government strives to provide quality education to its citizens and technology infrastructure has been developed swiftly throughout the kingdom. Similarly, privacy is another major issue for educational organizations so that educational data and students information are protected while learning online. Performance of online education has been important to the institutions and from the fig. 1 it appears that respondents gave importance to the performance whereas cloud services were also important.

We conclude from the data that our research question has been answered by identifying the issues like quality of education, privacy, performance and cloud control that have to be addressed continuously in order to provide seamless online education.

We also determined that overall public institutions were satisfied with the infrastructure and cloud services provided by service providers for online teaching due to Covid19 pandemic. However, there are some concerns for online assessments that need to be addressed in future.

\section{REFERENCES}

[1]. Wu, F., Zhao, S., Yu, B., Chen, Y.-M., Wang, W., Song, Z.-G., et al., (2020) "A new coronavirus associated with human respiratory disease in China" Nature, No. 575, pp. 265-269

[2]. www.spa.gov.sa/2050320 , Saudi Press Agency, [Accessed on July 16, 2020]

[3]. Lee, K, (2012) "Security threats in cloud computing environments", International journal of security and its applications, No. 6, 25

[4]. Shahzad, A., Golamdin, A., Ismail, N., (2016) "Opportunity and Challenges using the Cloud Computing in the Case of Malaysian Higher Education Institutions", The International Journal of Management Science and Information Technology, 20, pp. 1-18

[5]. Alberto, F., Daniel, P., José, B., and Francisco, H., (2012) "An Overview of E-Learning in Cloud Computing", Advances in Intelligent Systems and Computing, No. 173. 10.1007/978-3-642-30859-8_4

[6]. Khan, M. A., (2016) "A Hybrid Cloud Model for Higher Education Institutions in Saudi Arabia", 6th International Conference on Cloud Computing (CLOUDCOMP2015), LNICST, No. 167, pp. 255-259 
[7]. https://www.moe.gov.sa/en/HigherEducation, Guide to exams and evaluation arrangements Covid-19 [Accessed on July 27, 2020]

[8]. Yang, H. H., Feng, L., \& MacLeod, J. (2019) 'Understanding College Students' Acceptance of Cloud Classrooms in Flipped Instruction: Integrating UTAUT and Connected Classroom Climate", Journal of Educational Computing Research, No. 56, pp. 1258-1276

[9]. Fern'andez, A., D. Peralta, D., Herrera, F., and Ben'itez, J., (2012) "An Overview of E-Learning in Cloud Computing", L. Uden et al. (Eds.):Workshop on LTEC 2012, AISC, No. 173, pp. 35-46

[10]. Islam, N., Beer, M., and Slack, F., (2012) "E-Learning Challenges Faced by Academics in Higher Education: A Literature Review", Journal of Education and Training Studies, No. 3, pp. 102-112

[11]. Deepa, N., and Sathiyaseelan, R., (2012) "The Cloud and the Changing Shape of Education - Eaas (Education as a Service)", International Journal of Computer Applications, No. 42 , pp. $4-8$

[12]. Markert, J, (2004) "Demographics of age: Generational and cohort confusion", Journal of Current Issues and Research in Advertising, No. 26, pp. 11-25

[13]. Tagoe, M, (2012) "Students' perceptions on incorporating e-learning into teaching and learning at the University of Ghana", International Journal of Education and Development Using Information and Communication Technology, No. 1, pp. 91-103

[14]. Aldossary, S., and Allen, W., (2016) "Data Security, Privacy, Availability, and Integrity in Cloud Computing: Issues and Current Solutions", International Journal of Advanced Computer Science and Applications (IJACSA), No. 7, pp. $485-498$

[15]. Pushpa R., and Swapna K., (2012) "Issues \& Solution of SAAS Model in Cloud Computing" ,IOSR Journal of Computer Engineering (IOSR-JCE), pp. 40-44

[16]. Jiale Z., Bing C., Yanchao Z., Xiang C., and Feng H., (2018) "Data Security and Privacy-Preserving in Edge Computing Paradigm: Survey and Open Issues" , IEEE Access, No. 6, pp. 18209-18237

[17]. National e-learning center [www.nelc.gov.sa/en] Accessed on Sep 15, 2020

[18]. Majid, A., Elhadj, B., and Khawar, H., (2018) "Key Issues for Embracing the Cloud Computing to Adopt a Digital ransformation: A study of Saudi Public Sector", Procedia Computer Science, No. 130, pp. 1037-1043

[19]. Alshwaier, A., Youssef, A., and Emam, A., (2012) "A New Trend for E-Learning in KSA Using Educational Clouds", Advanced Computing: An International Journal, No. 3, pp. 81-97

[20]. Sultan, N., (2010) "Cloud computing for education: A new dawn?", International Journal of Information Management, No. 30, pp. 109-116

[21]. Patton, M., (2002) "Qualitative evaluation and research methods (3rd ed.)", Sage Publications, Inc.

[22]. Juma, M.K., and Tjahyanto, A., (2019) "Challenges of Cloud Computing Adoption Model for Higher Education in Zanzibar (the case study of suza and zu)", Procedia Computer Science, No.161, pp. 1046-1054

[23]. Mary, A. C., and Rose, A. L., (2019) "Implications, Risks and Challenges of Cloud Computing in Academic Field", International Journal of Scientific and Technology Research, No. 8, pp. 3268-3278

[24]. Aljaber, A. (2018) "E-learning policy in Saudi Arabia: challenges and successes", Research in Comparative and International Education, No. 13, pp. 176-194

[25]. Islam, N., Beer, M., and Slack, F., (2015) "E-Learning Challenges Faced by Academics in Higher Education: A Literature Review", Journal of Education and Training Studies, No. 3, pp. 47-53

[26]. Edeh, M. O., Nwafor, C. E., Ugwugbo, A. N., Rockson, K. A., Ogbonnaya, U. N., (2020) "Cloud Security Challenge: Implication on Education", International Journal of Computer Science and Mobile Computing, No. 9, pp.56-73

[27]. Al-Masaud, K., and Gawad, A., (2014) "Impediments of activating e-learning in higher education institutions in Saudi Arabia",. International Journal of Advanced Computer Science and Applications, No. 5, pp. 12-18

[28]. Al-Asmar, A., and Khan, M. (2014) "E-learning in Saudi Arabia: Past, present and future". Near and Middle Eastern Journal of Research in Education , No. 1, pp. 82-95 